\title{
Relationships between antioxidants, antioxidant enzyme activities and lipid peroxidation products during early development in Dentex dentex eggs and larvae
}

\author{
Gabriel Mourente ${ }^{a}$, Douglas R. Tocher ${ }^{b}$, Esther Diaz ${ }^{\mathbf{a}}$, Amalia Grauc and \\ Elena Pastorc
}

a Departmento de Biologia, Facultad de Ciencias del Mar, Universidad de Cadiz, Poligono Rio San Pedro, Apartado 40, 11510-Puerto Real, Cadiz, Spain

${ }^{b}$ NERC Unit of Aquatic Biochemistry, Institute of Aquaculture, University of Sirling, Stirling FK9 4LA, Scotland, U.K.

${ }^{c}$ Estacion de Acuicultura, Port d'Andraxt, Palma de Mallorca, Spain.

Corresponding author:

Dr. Douglas R. Tocher

NERC Unit of Aquatic Biochemistry

Insitute of Aquaculture

University of Stirling

Stirling FK9 4 LA

Scotland, U. K.

Tel: +44 1786 467996; Fax: +44 1786 472133; E-mail: drt1@stir.ac.uk 


\section{Abstract}

The overall aim is the characterization of the antioxidant systems in marine fish during early development in order to enhance growth and quality of early life stages by avoiding oxidation problems that may cause pathologies and disease. The present study determined the activities of the antioxidant system enzymes and levels of vitamin E, lipid peroxidation products and fatty acids during early development without exogenous feeding in the marine fish, Dentex dentex. Samples of fertilized eggs just prior to hatch, newly hatched larvae and unfed larvae up to day 9 after hatch were analysed on a daily basis.

The larvae did not grow during the experiment and by day 9 the surviving larvae weighed only a third of the newly hatched larvae. Lipid was a major energy source during this period of starvation as evidenced by greatly decreased amounts of total lipid due to a preferential utilisation of neutral lipids. All groups of fatty acids (saturated, monounsaturated and polyunsaturated) were consumed throughout the starvation period. Vitamin E levels were relatively constant until significantly declining by days 8 and 9 . Similarly, levels of lipid-soluble fluorescent products (LSFP) were relatively constant until day 6 and then significantly decreased from days 7 to 9 . In contrast, the level of malondialdehyde (MDA) was very high in eggs but was 3-fold lower in newly hatched larvae and then decreased over the whole time-course and was also significantly lower on days 8 and 9 .

The activities of enzymes of the antioxidation system were expressed in both eggs and early larvae and varied during the developmental period with levels of catalase and glutathione peroxidase (GPX) being initially low in eggs whereas glutathione-Stransferase (GST) and superoxide dismutase (SOD) were higher in eggs than in larvae. Overall, the activities of catalase and GPX increased, whereas GST and total SOD activities decreased, during the early stages of development during a period where there was no exogenous dietary input into the larvae. Glutathione reductase activity was very low and showed an increasing trend initially until days 2-3 before declining and varying over the remaining period.

In conclusion, we determined the prooxidant (polyunsaturated fatty acid) status, antioxidant status (vitamin E), peroxidation status (MDA and LSFP) and the activities of the antioxidant enzyme systems in a single integrated study in unfed marine fish larvae during early development.

Keywords: Dentex dentex; Larvae; Antioxidant Enzymes; Assays, Vitamin E, Malondialdehyde (MDA), Lipid-Soluble Fluorescent Products (LSFP). 


\section{Introduction}

Tissue lipid polyunsaturated fatty acid (PUFA) content and composition are critical factors in lipid peroxidation, and as fish tissues contain large quantities of highly unsaturated n-3 series fatty acids they may be more at risk from peroxidative attack than are mammals (Bell and Cowey, 1985). Therefore, although PUFA are essential for optimal growth and development of marine fish, they also impose a peroxidation burden on the fish. In normal physiological conditions there is continuous production of reactive oxygen species (ROS) which induce oxidative stress and can result in damage to cell membranes, inactivation of enzymes and damage to genetic material and other vital cell components. Lipid peroxidation, specifically PUFA oxidation induced by ROS and free radicals, is acknowledged as being highly deleterious, resulting in damage to cellular biomembranes, particularly those of subcellular organelles, which contain relatively large amounts of PUFA (Tappel, 1975) and is the most extensively studied component of oxidative damage to biological systems. The double bonds in PUFA contain hydrogens with bond energies that, in the presence of reactive oxygen species or other free radicals, make them highly susceptible to hydrogen abstraction reactions that initiate and propagate a chain reaction known generally as autoxidation (Gardner, 1989; Porter et al., 1995). Autoxidation of PUFA produces compounds such as fatty acid hydroxyperoxides, fatty acid hydroxides, aldehydes such as malondialdehyde (MDA) and hydrocarbons. These reactions also produce lipid peroxide related fluorophores, such as lipofuscin, which are collectively termed lipid-soluble fluorescent products (LSFP), formed by aldehyde-protein crosslinking of carbonyl

and amino groups, which are common in biology and as they have also been related to the aging process are sometimes termed fluorescent age pigments (FAP) (Sohal and Wolfe, 1986; Sohal and Brunk, 1990; Yin, 1995).

To maintain health and prevent oxidation-induced lesions and mortalities, there must be effective antioxidation systems operating fish. The components of these systems involve antioxidant compounds such as NADH/NADPH, glutathione (GSH), protein sulphydryl (-SH) 
groups and uric acid and dietary micronutrients such as vitamins $\mathrm{E}$ and $\mathrm{C}$ or carotenoids. Other components are the antioxidant enzymes including free radical scavenging enzymes such as catalase, superoxide dismutase (SOD) and glutathione peroxidase (GPX) and associated enzymes such as glutathione-S-transferase (GST) and glutathione reductase (GR). However, information in relation to in vivo lipid peroxidation and antioxidant defences either in wild or cultured fish species is quite limited (Murata and Yamauchi, 1989; Sekiya et al., 1991; Sakai et al., 1992; Murata et al., 1996). In addition, most of the studies have been done in salmonids and freshwater fish (Bell et al., 1984, 1985, 1987; Cowey et al., 1985; Radi et al., 1987; Roy et al., 1995) with few studies in marine fish (Stéphan et al., 1995; Murata et al., 1996). In fish, in vivo lipid peroxidation caused by oxygen radicals is a principal cause of several diseases such as jaundice (Sakai et al., 1989), nutritional muscular dystrophy (Watanabe et al., 1970; Murai and Andrews, 1974) and hemolysis (Kawatsu, 1969). In addition, it is well known and generally acknowledged that many biological and physiological systems are poorly developed in larval marine fish, therefore, it is possible that newly-hatched and early larval marine fish may not have sufficiently well-developed antioxidant capability both in terms of metabolic systems and/or antioxidant nutrient status.

The overall objective of our project was the characterization of the antioxidant system in marine fish during early development in order to understand how to avoid oxidation problems that may cause pathologies and disease and to enhance growth and quality of early life stages. The specific aim of the present study was to determine the pattern of expression of the antioxidant enzymes and their relationships with each other, other components of the antioxidant system such as vitamin E and lipid peroxidation products in the early stages of development of the marine fish, the common dentex. The fish were not offered food during the experiment to avoid the effects of input of exogenous components, particularly prooxidant PUFA and antioxidant vitamins.

\section{Materials and methods}




\subsection{Materials}

High-performance thin-layer chromatography (HPTLC) plates $(10 \times 10 \times 0.15 \mathrm{~mm})$, precoated with silica gel 60 were obtained from Merck (Darmstadt, Germany). All solvents were of HPLC grade and were obtained from Rathburn Chemicals Ltd. (Walkerburn, U.K.). $\mathrm{KH}_{2} \mathrm{PO}_{4}$, $\mathrm{K}_{2} \mathrm{HPO}_{4}$, EDTA, adrenaline, xanthine, potassium cyanide, reduced and oxidised glutathione, NADPH, hydrogen peroxide, cumene hydroperoxide, 1-chloro 2,4 dinitrobenzene, oxidised glutathione, sodium azide, glutathione reductase, xanthine oxidase and butylated hydroxytoluene (BHT) were purchased from Sigma Chemical Co. Ltd., Poole, Dorset.

\subsection{Broodstock management, egg and larval production}

Broodstock maintenance and reproduction as well as egg and larval production were performed according to the methodology developed for Dentex dentex by Pastor et al. (1995) at the Estación de Acuicultura, Port d'Andraxt, Palma de Mallorca, Spain. Eggs were hatched in 4001 cylindro-conical tanks in an open circulation system (1/3 water exchange/day) at a density of 100 eggs / 1, hatching occurring about $30 \mathrm{~h}$ after spawning. Newly-hatched larvae developed at the expense of yolk-sac and oil drop reserves and subsequent starvation until day 9 after hatch. Full details of energy utilization and bioenergetics in dentex larvae during lecitotrophia and starvation are published elsewhere (Mourente et al. 1998).

\subsection{Sample collection and dry weight determination}

Eggs from the same batch, approximately 10-12 $\mathrm{h}$ after spawning were collected with an adequate size mesh screen, rinsed in distilled water and blotted on filter paper before being frozen in liquid nitrogen and stored in the freezer at $-80^{\circ} \mathrm{C}$ until analysis. The same treatment was used 
for larvae from 1 to 9 days after hatching. Yolk sac and oil drop absorption had primarily occurred in larvae sampled by day 5 and by day 6 after hatching, respectively.

Replicates of preweighed samples (approximately $500 \mathrm{mg}$ wet weight of eggs and 1 to 9 days post-hatch unfed larvae) were maintained at $110{ }^{\circ} \mathrm{C}$ for $24 \mathrm{~h}$. The dry weights were determined after cooling in vacuo for at least $1 \mathrm{~h}$.

\subsection{Lipid content, lipid class and fatty acid analyses}

Total lipid contents of the eggs and larvae were determined gravimetrically after extraction with chloroform/methanol (2:1, v/v) essentially by the method of Folch et al. (1957). All solvents contained $0.01 \%$ BHT as antioxidant.

Lipid classes were separated by one-dimensional, double-development HPTLC using methyl acetate/propan-2-ol/chloroform/methanol/0.25\% aqueous $\mathrm{KCl}$ (25:25:25:10:9, by vol.) and hexane/diethyl ether/acetic acid (85:15;1.5, by vol.) as developing solvents as described previously (Tocher and Harvie, 1988). Lipid classes were quantified by charring followed by calibrated scanning densitometry using a Shimadzu CS-9001PC dual wavelength flying spot scanner (Olsen and Henderson, 1989).

Fatty acid methyl esters were prepared from total lipid by acid-catalyzed transmethylation at $50{ }^{\circ} \mathrm{C}$ for $16 \mathrm{~h}$ using tricosanoic acid (23:0) as internal standard (Christie, 1982) and were extracted and purified as described previously (Tocher and Harvie, 1988). Methyl esters were analyzed in a Hewlett-Packard 5890A gas chromatograph equipped with a chemically bonded (PEG) Omegawax-320 fused silica wall-coated capillary column (30 m x $0.32 \mathrm{~mm}$ i.d., Supelco Inc., Bellefonte, USA) and using on-column injection. Hydrogen was used as carrier gas with an oven thermal gradient from an initial $50^{\circ} \mathrm{C}$ to $180{ }^{\circ} \mathrm{C}$ at $25^{\circ} \mathrm{C} / \mathrm{min}$ and then to a final temperature of $235^{\circ} \mathrm{C}$ at $3{ }^{\circ} \mathrm{C} / \mathrm{min}$. The final temperature was maintained for $10 \mathrm{~min}$. Individual fatty acid methyl esters were identified by comparison with known standards and a wellcharacterized fish oil and by reference to published data as described previously (Tocher and 
Harvie, 1988) and were quantified by means of a PC linked to the gas chromatograph and utilising Hewlett-Packard 3365 ChemStation software. All solvents contained $0.01 \%$ BHT as an antioxidant.

2.5. Determination of catalase, superoxide dismutase, glutathione peroxidase, glutathione $S$ transferase and glutathione reductase activities in egg and larval homogenates.

Samples of eggs and larvae were homogenised in 9 volumes of $20 \mathrm{mM}$ phosphate buffer $\mathrm{pH} 7.4$, $1 \mathrm{mM}$ EDTA and $0.1 \%$ Triton $\mathrm{X}-100$ and the homogenates centrifuged at $600 \mathrm{xg}$, to remove debris, and the resultant supernatants used directly for enzyme assays.

Catalase (EC 1.11.1.6) activity was measured by following the reduction of hydrogen peroxide at $240 \mathrm{~nm}$ using the extinction coefficient $0.04 \mathrm{mM}^{-1} \mathrm{~cm}^{-1}$ (Beers and Sizer, 1952). Immediately before assay, $50 \mathrm{ml}$ of $67 \mathrm{mM}$ potassium phosphate buffer $\mathrm{pH} 7.0$ was mixed with $80 \mu \mathrm{lof} 30 \%$ (v/v) hydrogen peroxide. The quartz assay cuvette contained $3.0 \mathrm{ml}$ of the above buffered hydrogen peroxide solution plus $25 \mu$ l of sample.

Total SOD (EC 1.15.1.1) activity was assayed by measuring the inhibition of the oxygendependent oxidation of adrenalin (epinephrine) to adenochrome by xanthine oxidase plus xanthine (Panchenko et al., 1975). Plastic mini-cuvettes containing $0.5 \mathrm{ml}$ of $100 \mathrm{mM}$ potassium phosphate buffer pH $7.8 / 0.1 \mathrm{mM}$ EDTA, $200 \mu \mathrm{l}$ adrenaline, $200 \mu \mathrm{l}$ xanthine and $50 \mu \mathrm{l}$ distilled water (uninhibited control) or $50 \mu \mathrm{l}$ sample were prepared and the reaction initiated by the addition of $10 \mathrm{ml}$ xanthine oxidase. The reaction was followed at $480 \mathrm{~nm}$ and 1 unit of SOD activity is described as the amount of the enzyme which inhibits the rate of adenochrome production by $50 \%$.

GPX (EC 1.11.1.9) was assayed by following the rate of NADPH oxidation at $340 \mathrm{~nm}$ by the coupled reaction with glutathione reductase (Bell et al., 1985). Plastic mini-cuvettes containing $0.75 \mathrm{ml}$ of $60 \mathrm{mM}$ potassium phosphate buffer $\mathrm{pH}$ 7.4/1 mM EDTA/2 mM sodium azide, $50 \mu \mathrm{l}$ reduced glutathione, $100 \mu \mathrm{l}$ NADPH and $5 \mu \mathrm{l}$ glutathione reductase were prepared. The basal 
reaction was initiated by the addition of either $50 \mu \mathrm{l} \mathrm{H}_{2} \mathrm{O}_{2}$ solution or $50 \mu \mathrm{l}$ cumene hydroperoxide (as substrates for selenium-dependent and total GPX activities). The non-enzymic rate without sample added was measured for later subtraction. Sample $(50 \mu l)$ was added and the assay continued by measuring absorbance at $340 \mathrm{~nm}$ with specific activities determined using the extinction coefficient of $6.22 \mathrm{mM}^{-1} \mathrm{~cm}^{-1}$.

GST activity was determined by following the formation of glutathione-CDNB adduct at 340 nm. Standard plastic cuvettes containing $2.5 \mathrm{ml}$ of $120 \mathrm{mM}$ potassium phosphate buffer $\mathrm{pH} 6.5$, $100 \mu \mathrm{l} \mathrm{GSH}$ and $100 \mu \mathrm{l} \mathrm{CDNB}$ were prepared and the reaction initiated by the addition of $50 \mu \mathrm{l}$ sample. Specific activities were determined using an extinction coefficient of $9.6 \mathrm{mM}^{-1} \cdot \mathrm{cm}^{-1}$.

GR (EC 1.6.4.2) activity was determined by the oxidation of NADPH at $340 \mathrm{~nm}$ using the extinction coefficient $6.22 \mathrm{mM}^{-1} \cdot \mathrm{cm}^{-1}$. Plastic mini-cuvettes containing $0.6 \mathrm{ml}$ of $0.2 \mathrm{M}$ potassium phosphate buffer pH7.0/2 mM EDTA, $200 \mu$ l oxidised glutathione and $100 \mu \mathrm{NADPH}$ were prepared and the reaction initiated by the addition of $100 \mu$ of sample.

Protein content in the egg and larval homogenates was determined by the Folin-phenol reagent method, according to Lowry et al. (1951) following digestion in $\mathrm{NaOH} / \mathrm{SDS}$.

\subsection{Determination of vitamin E ( $\alpha$-tocopherol)}

$\alpha$-Tocopherol in fish tissues was determined, after saponification and extraction, largely as described by Cowey et al. (1981) using the HPLC method of Hung et al. (1980). Briefly, weighed samples were homogenised in $5 \mathrm{ml}$ of $2 \%(\mathrm{w} / \mathrm{v})$ ethanolic pyrogallol and the homogenate incubated for $5 \mathrm{~min}$ at $70^{\circ} \mathrm{C}$. One $\mathrm{ml} 60 \% \mathrm{KOH}(\mathrm{w} / \mathrm{v})$ was added, the tubes flushed with nitrogen, stoppered, and incubation at $70^{\circ} \mathrm{C}$ continued for a further $20 \mathrm{~min}$. After cooling, 4 $\mathrm{ml}$ of water and $4 \mathrm{ml}$ of hexane/BHT were added and the tubes mixed vigorously . Three $\mathrm{ml}$ of the hexane layer was removed, evaporated under a stream of nitrogen and redissolved in $1 \mathrm{ml}$ methanol. Reverse-phase HPLC separation was carried out using a Spherisorb ODS2 column $(4.6 \times 250 \mathrm{~mm})$, eluted with $98 \%$ methanol at a flow rate of $1.5-2.0 \mathrm{ml} / \mathrm{min}$ with $\mathrm{UV}$ detection at 
$293 \mathrm{~nm}$.

\subsection{Determination of malondialdehyde (MDA) and lipid-soluble fluorescent products} $(L S F P)$

Weighed samples were homogenised in $9 \mathrm{ml}$ of $50 \mathrm{mM}$ potassium phosphate buffer, $\mathrm{pH}$ 7.4. One $\mathrm{ml}$ of homogenate was added to a mixture of $2 \mathrm{ml} 10 \%(\mathrm{w} / \mathrm{v})$ trichloroacetic acid, $2 \mathrm{ml} 1 \%(\mathrm{w} / \mathrm{v})$ thiobarbituric acid and $0.05 \mathrm{ml} \mathrm{0.2 \% (w/v)} \mathrm{BHT} \mathrm{(in} \mathrm{ethanol).} \mathrm{The} \mathrm{tube} \mathrm{contents} \mathrm{were} \mathrm{mixed} \mathrm{and}$ heated at $100^{\circ} \mathrm{C}$ for $20 \mathrm{~min}$, centrifuged, the supernatants transferred to plastic cuvettes and the absorbance recorded against a reagent blank at $532 \mathrm{~nm}$. The concentration of MDA was obtained using the extinction coefficient $1.56 \times 10^{5} \mathrm{M}^{-1} . \mathrm{cm}^{-1}$ (Rossell, 1989).

Fluorescent lipid peroxidation products (LSFP) such as lipofuscin, were quantified spectrofluorometrically, after removal of interfering fluorescent compounds (primarily retinol and flavins) and linearity determination, in total lipid chloroform/methanol extracts by a modification of Fletcher et al. (1973). Quinine sulphate at a concentration of $1 \mu \mathrm{g} / \mathrm{ml}$ in $0.1 \mathrm{M}$ sulphuric acid was used as a standard for fluorescence intensity and wavelength calibration (Hammer and Braum, 1988). The production of LSFP were measured using excitation/emission wavelengths of 350/445 $\mathrm{nm}$ and 400/455 $\mathrm{nm}$ which are characteristic of lipid complexes formed by the cross linking of the aldehyde groups of MDA with amino groups of phosphatidylserine and phosphatidylethanolamine, respectively (Jain, 1988).

\subsection{Statistical analysis}

Results are presented as means \pm SD $(n=3$ or 4$)$. The data were checked for homogeneity of the variances by the Bartlett test and, where necessary, the data were arc-sin transformed before further statistical analysis. Differences between mean values were analyzed by one-way analysis of variance (ANOVA), followed when pertinent by a multiple comparison test (Tukey). 
Differences were reported as statistically significant when $\mathrm{P}<0.05$ (Zar, 1984).

\section{Results}

The data for dry weight, lipids, vitamin E and lipid peroxidation products are all presented on an absolute content per individual larva basis to enable direct comparison of the respective levels. The average dry weight of newly-hatched larvae (L0) was approximately $86 \%$ of the egg dry weight (Fig.1). The individual dry weight of the larvae decreased during the period of starvation with the average weight of larvae on day 9 (L9), the last day on which a sample could be taken due to mortalities, being less than one third of the newly-hatched larvae. The total lipid content of the larvae decreased continuously during the experimental period with only $15 \%$ of the total lipid present in newly-hatched larvae remaining in the larvae just prior to death by starvation (Fig.1). Lipid was preferentially utilised in the larvae as the lipid remaining in 9 day-old larvae accounted for only $14.4 \%$ of the total dry weight of the larvae compared with $32 \%$ of the total dry weight in newly-hatched larvae. Yolk sac and oil drop resorption had primarily occurred in larvae sampled by day 5 and by day 6 after hatching, respectively (Mourente et al., 1998). Both neutral and polar lipids were depleted during the experimental period although neutral lipids were preferentially utilised with only $8 \%$ of the total neutral lipid reserves, compared with $28 \%$ of the total polar lipids present in newly-hatched larvae remaining in day 9 larvae (Fig.1). The larval content of all the fatty acid groups, saturated (SFA), monounsaturated (MUFA) and polyunsaturated (PUFA), decreased over the period of the experiment. MUFA were slightly preferred for utilisation as only $6 \%$ of reserves existing in newly-hatched larvae remained in day 9 larvae, compared with 11\% PUFA and 14\% SFA (Fig.1). It was noteworthy, however, that the relative proportion of PUFA remained almost constant only increasing from $50.2 \%$ in newlyhatched larvae to $52.9 \%$ in day 9 larvae. Further details of energy the bioenergetics in dentex larvae during lecitotrophia and starvation are published elsewhere (Mourente et al. 1998). 
The vitamin E content remained relatively constant over most of the experimental period before declining sharply in the last two days (Fig.2). The level was significantly reduced in day 9 larvae, and was less than half that present in eggs or newly-hatched larvae. However, the amount of vitamin E relative to the amount of PUFA in the larvae increased during the duration of the experiment (Fig.3).

The level of lipid peroxides, as indicated by assayable malondialdehyde (MDA), was very high in fertilised eggs prior to hatching and was significantly higher than in larvae (Fig.2). The larval content of MDA decreased significantly during the period of the experiment (Fig.2). The ratio of MDA to PUFA in the eggs was greater than 5 whereas the ratio in larvae was much lower and generally increased during the experimental period rising from approximately 1.6 in newly-hatched larvae to 2.4 in day 9 larvae (Fig.3). LSFP, characteristic of peroxidised phosphatidylethanolamine (400-455 nm) was relatively constant before decreasing significantly on days 7-9 (Fig.2). LSFP characteristic of peroxidised phosphatidylserine $(350-445 \mathrm{~nm})$, showed a similar pattern but at a much lower level consistent with the much lower level of tissue phosphatidylserine (Fig.2). The ratio of total LSFP to PUFA increased 3-fold from the egg to days 5/6 post-hatch before declining (Fig.3).

The activities of various enzymes of the antioxidation system in eggs and unfed larvae of Dentex dentex larvae over 9 days are shown in Fig. 4. All enzyme activities are expressed relative to protein content. Although the protein content of larvae was lower than in eggs, as expected due to the loss of the chorion and perivitelline fluids, the proportion of protein was relatively constant during the larval stages (Mourente et al. 1998). Catalase activity did not alter upon hatching and was constant for the first 2 days after hatching but increased over 3-fold from then to day 9 larvae with large increases just prior to yolk sac resorption (L3) and between days 7 and 8 (Fig. 4). Similarly, GPX activities to both hydrogen peroxide and cumene hydroperoxide substrates were low in both eggs and newly-hatched larvae and remained relatively constant until day 4 when 
both activities markedly increased by approximately 10-fold and then remained at this higher level until day 9 (Fig. 4). In contrast, the activity of GST decreased by about $50 \%$ over the period of the experiment with the largest decrease occurring over days 3-5 (Fig. 4). Similarly, total SOD activity decreased during the course of the experiment although in this case the greatest reduction in activity was between the egg and newlyhatched larvae (Fig. 4). GR activity was considerably lower than the other enzyme activities measured as $\mu \mathrm{mol} / \mathrm{min} / \mathrm{mg}$ protein and after an initial increase up to approximately yolk sac absorption it decreased to a level on day 9 similar to the level in eggs (Fig. 4).

\section{Discussion}

There have been many studies on the endogenous antioxidant enzyme systems in fish (Roche and Boge, 1993; Murata et al., 1996) particularly in relation to specific oxidative stresses (Pedrajas et al., 1995; Rana and Singh, 1996) but also including studies in relation to age and development (Otto and Moon, 1996). However, there have been few studies specifically investigating the activity of the enzyme systems in larval stages (Aceto et al., 1994; Peters et al., 1994; Peters and Livingstone, 1996). The present study has shown that readily measurable amounts of all the antioxidant system enzymes were present in Dentex dentex eggs prior to hatching. In particular, the eggs contained substantial catalase, SOD and GST activities. Along with almost $60 \mathrm{pg}$ vitamin E per egg, this suggests that the eggs were well protected against peroxidation despite the very high level of PUFA that they contained. In particular, in catalase and SOD, the eggs had the primary enzyme activities responsible for the breakdown and inactivation of the main metabolically-produced endogenous radicals, hydrogen peroxide and superoxide. However, the eggs also contained a relatively high level of MDA but upon hatching the larval level of MDA was only about one third of that present in the unhatched egg. 
Therefore, it appeared that two thirds of the MDA was not associated with the developing larval body but rather may have been associated with the chorion and/or perivitelline fluid. This situation may reflect accumulation of MDA during embryonic development with excretion from the developing embryo into the perivitelline fluid which was lost upon hatching. Subsequently, MDA levels decreased over the whole time-course of larval development perhaps reflecting decreased accumulation through enhanced antioxidant systems and/or increased excretion rate.

After hatching, the activities of catalase and SOD varied differentially with catalase generally increasing and SOD generally decreasing during early larval development in the common dentex. The reason for the activity of SOD and catalase varying inversely in relation to each other is perhaps not immediately apparent as SOD, by converting superoxide to hydrogen peroxide, directly provides substrate for catalase (Miller et al., 1993). Previously, it had been shown that catalase activity increased after hatching in rainbow trout fry (Aceto et al., 1994) and from embryos to 11 days post-hatch larvae in turbot (Peters and Livingstone, 1996). Similarly, the activity of SOD also decreased from embryos to 11 days post-hatch larvae in turbot (Peters and Livingstone, 1996) whereas, in contrast, the opposite was observed in rainbow trout where SOD activity was lower in the eggs prior to hatching (Aceto et al., 1994).

The activity of GPX, whether measured against hydrogen peroxide or cumene hydroperoxide, was initially low in unhatched eggs but, like catalase, it increased during larval development. Interestingly, the largest increase in the activity of GPX occurred between days 3 and 4 post-hatch, just after the activity of catalase also showed its largest increase between days 2 and 3 post-hatch. Therefore, these increases occurred before yolk sac absorption (day 5 post-hatch) and disappearance of the oil globule (day 6) and, in addition, there was no correlation between these increases in enzyme activities and fatty acid composition, which declined steadily, or vitamin E, which was relatively constant during this period. Therefore, the increased levels of catalase and GPX may be 
in response to other metabolic changes occurring at this time possibly leading to changed sources of oxidative stress. In this respect perhaps, it was noteworthy that the activity of selenium-dependent GPX (hydrogen peroxide substrate) and total GPX activity (cumene hydroperoxide substrate) almost exactly parallel each other indicating that there was very little evidence for a selenium-independent GPX activity. Despite the increasing activity of GPX, which would result in increased production of oxidised glutathione (GSSG), the activity of GR, which had the lowest activity of all the enzymes assayed but is nonetheless essential for the regeneration of reduced glutathione (GSH) (Miller et al., 1993), was not well correlated with the activity of GPX in dentex larvae. This imbalance in GPX and GR activities could potentially lead to GSSG accumulation and a lower GSH/GSSG ratio. GSSG is known to be an inhibitor of protein synthesis and other enzyme activities and cells normally maintain a high GSH/GSSG ratio (Halliwell and Gutteridge, 1989). However, as we did not assay glutathione or $\gamma$ glutamyltransferase, which degrades GSH, affects on the GSH/GSSG ratio are speculative.

The activity of GST showed a marked decline throughout the development of dentex larvae. GST operates as an enzyme of the antioxidant system by conjugating peroxy radicals with glutathione although it is thought that this pathway may only be significantly important in conditions of selenium or vitamin E deficiency (Miller et al., 1993). However, in the present study the larvae were starving and so although they were potentially selenium deficient, at least in the latter stages, and the data clearly showed that the larval vitamin $\mathrm{E}$ level decreased greatly in the latter stages, the activity of GST did not increase.

The collapse in vitamin E level in the developing larvae between days 7 and 9 posthatch indicated that vitamin E was being consumed rapidly at this stage in the process of quenching free radicals and chain-breaking. It was particularly interesting that the collapse in vitamin E levels only occurred after yolk-sac resorption and disappearance of 
the oil globule. These processes may be related as there may be transient increase in PUFA into the metabolically active pool at this time due to resorption of yolk PUFA and that cannot be incorporated into membranes in starving animals and therefore must be oxidised. Catalase activity also increased greatly at this time and there may also be a slight increase in SOD activity.

Despite the complex variations in antioxidant enzyme activities, it was noteworthy that the levels of peroxidation products whether measured as MDA or as LSFP actually decreased during the overall development of starving dentex larvae. LSFP levels were particularly interesting as they tended to parallel vitamin E levels in that they were relatively constant until after yolk sac resorption and disappearance of the oil globule after which point they declined rapidly and significantly. This has been observed previously in pike larvae in which LSFP (termed fluorescent age pigments, FAP, in that study) concentrations reached a maximum at yolk sac resorption and declined thereafter (Hammer, 1988). Hammer (1993) related the decrease in FAP to a state of nutritional deprivation in the pike larvae after yolk sac resorption. Along with data relating FAP accumulation to incubation temperature, these data gave rise to the hypothesis that FAP concentrations reflected larval metabolic activity (Hammer, 1993). As with pike larvae, the present study suggested that LSFP can be metabolized and removed during a state of nutritional deprivation in common dentex larvae. However, it cannot be excluded that the LSFP levels measured may also be influenced by mortalities of larvae with very high LSFP levels and preferential survival of larvae with lower LSFP levels.

MDA levels in vivo are probably maintained very low due to the action of aldehyde dehydrogenases or oxidases and the MDA level measured by the assay is actually due to MDA formed by the breakdown of lipid peroxides in the sample (Halliwell and Gutteridge, 1989; Miller et al., 1993). Overall though, the results of the present study show that lipid peroxidation products were not accumulating in the developing larvae. Whether or not this was due to the balanced activities of the antioxidant enzymes and 
antioxidants such as vitamin $\mathrm{E}$ in a closed system, as the starving larvae essentially were, is debatable. Total PUFA levels also declined consistently throughout the period from hatch to day 9 post-hatch and so a major substrate for peroxidative attack was also decreasing. Hence, the vitamin E/PUFA ratio increased during the experimental period and did not decrease greatly even when the vitamin E level collapsed over days 7-9 posthatch. Therefore, the evidence suggests that in larvae, under conditions with no exogenous dietary input, peroxidation may not be a significant additional stress.

In conclusion, we determined the effect of early development without exogenous feeding on the prooxidant (PUFA) status, antioxidant status (vitamin E), peroxidation status (MDA and LSFP) and the activities of the antioxidant enzyme systems in a single integrated study in larvae of a marine fish, the common dentex. The activities of the antioxidant enzymes were expressed in both eggs and early larvae and varied during the developmental period with the levels of catalase and GPX being initially low in eggs whereas GST and SOD were higher in eggs than in larvae. Overall, the activities of catalase and GPX increased, whereas GST and total SOD activities decreased, during the early stages of development. These data suggested that SOD was perhaps relatively more important in eggs than in larvae; catalase activity, which is very high in comparison to the other activities, is important at all stages; and that a putative role for GST in lipid hydroperoxide metabolism in eggs is replaced by GPX in larvae. The enzyme activities appeared not to be directly related to the prooxidant load or the levels of lipid peroxidation products as measured by MDA and LSFP levels although increasing larval catalase and GPX activities may be related to the declining levels of lipid oxidation products in the larvae. Similarly, there was no direct relationship between antioxidant (vitamin E) levels and peroxidation products in the present study. The evidence suggested that lipid peroxidation may not be a significant additional stress in marine fish larvae under conditions with no exogenous dietary input. 


\section{Acknowledgements}

This work was funded by the Spanish Ministry of Education and Culture (Project CYTMAR ref n MAR95-1920-C02-01) and (Acciones Integradas Hispàno-Británicas ref.n º HB1996-0013) and the British Council (Acciones Integradas ref.nº MDR/(1997-98)/2233).

\section{References}

Aceto, A., Amicarelli, F., Saccetta, P., Dragani, B., Bucciarelli, T., Masciocco, L., Miranda, M., Di Ilio, C., 1994. Developmental aspects of detoxifying enzymes in fish. Free Radical Res. $21,285-294$.

Beers, R.F., Sizer, I.W., 1952. Spectrophotometric method for measuring the breakdown of hydrogen peroxide by catalase. J. Biol. Chem. 195, 133-140.

Bell, J.G., Cowey, C.B., 1985. Roles of vitamin E and selenium in the prevention of pathologies related to fatty acid oxidation in salmonids. In: Cowey, C.B., Mackie, A.M., Bell, J.G. (Eds.), Nutrition and Feeding in Fish. Academic Press, London, pp. 333-347.

Bell, J.G., Cowey C.B., Youngson, A., 1984. Rainbow trout liver microsomal lipid peroxidation. The effect of purified glutathione peroxidase, glutathione S-transferase and other factors. Biochim. Biophys. Acta 795, 91-99.

Bell, J.G., Cowey, C.B., Adron, J.W., Shanks, A.M., 1985. Some effects of vitamin E and selenium deprivation on tissue enzyme levels and indices of tissue peroxidation in rainbow trout (Salmo gairdneri) . Br. J. Nutr. 53, 149-157.

Bell, J.G., Cowey, C.B., Adron, J.W., Pirie, B.J.S., 1987. Some effects of selenium deficiency on enzyme activities and indices of tissue peroxidation in Atlantic salmon parr (Salmo salar). Aquaculture 65, 43-54.

Christie, W.W., 1982. Lipid Analyses, 2nd Edition, Pergamon Press, Oxford.

Cowey, C.B., Bell, J.G., Knox, D., Fraser A., Youngson, A., 1985. Lipids and antioxidant 
systems in developing eggs of salmon (Salmo salar). Lipids 20, 567-572.

Cowey, C.B., Adron, J.W., Walton, M.J., Murray, J., Youngson, A., Knox, D., 1981. Tissue distribution, uptake, and requirement for $\alpha$-tocopherol of rainbow trout (Salmo gairdneri) fed diets with a minimal content of unsaturated fatty acids. J. Nutr. 111, 1556-1567.

Fletcher, B.L., Dilard, C.J., Tappel, A.L., 1973. Measurement of fluorescent lipid peroxidation products in biological systems and tissues. Anal. Biochem. 52, 1-9.

Folch, J., Lees, M., Sloane Stanley, G.H., 1957. A simple method for the isolation and purification of total lipids from animal tissues. J. Biol. Chem. 226, 497-509.

Gardner, H.W., 1989. Oxygen radical chemistry of polyunsaturated fatty acids. Free Radical Biol. Med. 7, 65-86.

Halliwell, B., Gutteridge, J.M.C., 1989. Free Radicals in Biology and Medicine, 2nd Edition. Oxford University Press, 543 pp.

Hammer, C., 1988. Accumulation of fluorescent age pigments in embryos and larvae of pike, Esox lucius (Esocidae, Teleostei) at different incubation temperatures. Environ. Biol. Fish. 22, 91-99.

Hammer, C., 1993. Accumulation patterns of fluorescent age pigments in fish larvae. In: Schroder, J., Bauer, J., Scharte, M. (Eds.), Trends in Ichthyology, An International Perspective. Blackwell Scientific Press, Oxford, pp. 201-210.

Hammer, C., Braum, E., 1988. Quantification of age pigments (lipofuscin). Comp. Biochem. Physiol. 90B, 7-17.

Hung, S.S.O., Cho, C.Y., Slinger, S.J., 1980. High performance liquid chromatographic determination of $\alpha$-tocopherol in fish liver. J. Assoc. Off. Anal. Chem. 63, 889-893.

Jain, S.K., 1988. Evidence for membrane lipid peroxidation during the in vivo aging of human erythrocytes. Biochim. Biophys. Acta 937, 205-210.

Kawatsu, H., 1969. Studies on the anemia of fish-III. An example of macrcytic anemia found in brook trout, Salvelinus fontinalis. Bull. Freshwater Res. Lab. 19, 161-167.

Lowry, O.H., Rosebrough, N.J., Farr, A.L., Randall, R.J., 1951. Protein measurement with Folin- 
phenol reagent. J. Biol. Chem. 193, 265-275.

Miller, J.K., Brzezinska-Slebodzinska, E., Madsen, F.C., 1993. Oxidative stress, antioxidants, and animal function. J. Dairy Sci. 76, 2812-2821.

Mourente, G., Rodriguez, A., Grau, A., and Pastor, E., 1998. Utilization of lipids by Dentex dentex L. (Osteichthyes, Sparidae) larvae during lecitotrophia and subsequent starvation. Fish Physiol. Biochem. in press.

Murai, T., Andrews, J.W., 1974. Interaction of dietary $\alpha$-tocopherol, oxidized menhaden oil and ethoxyquin on channel catfish (Ictalurus punctatus). J. Nutr. 104, 1416-1431.

Murata, H., Yamauchi, K., 1989. Relationship between the 2-thiobarbituric acid values of some tissues from cultured red sea bream and its dietary $\alpha$-tocopherol. Nippon Suisan Gakkaishi $55,1435-1439$.

Murata H., Sakai, T., Yamauchi, K., Ito, T., Tsuda, T., Yoshida, T., Fukudome, M., 1996. In vivo lipid peroxidation levels and antioxidant activities of cultured and wild yellowtail. Fisheries Science 62, 64-68.

Olsen, R.E., Henderson, R.J., 1989. The rapid analysis of neutral and polar marine lipids using double-development HPTLC and scanning densitometry. J. Exp. Mar. Biol. Ecol. 129, 189197.

Otto, D.M.E., Moon, T.W., 1996. Endogenous antioxidant systems of two teleost fish, the rainbow trout and the black bullhead, and the effect of age. Fish Physiol. Biochem. 15, 349358.

Panchenko, L.F., Brusov, O.S., Gerasimov, A.M., Loktaeva, T.D., 1975. Intramitochondrial localization and release of rat liver superoxide dismutase. FEBS Lett. 55, 84-87.

Pastor, E., Riera, F., Pou, S., Grau A.M., Grau, A., 1995. Summary of investigations on reproduction and larval rearing of common dentex (Dentex dentex L.). ICES Mar. Sci. Symp. $201,148-152$.

Pedrajas, J.R., Peinado, J., Lopez-Barea, J., 1995. Oxidative stress in fish exposed to model xenobiotics. Oxidatively modified forms of $\mathrm{Cu}, \mathrm{Zn}$-superoxide dismutase as potential 
biomarkers. Chem. Biol. Interact. 98, 267-282.

Peters, L.D., Livingstone, D.R., 1996. Antioxidant enzyme activities in embryologic and early larval stages of turbot. J. Fish Biol. 49, 986-997.

Peters, L.D., Porte, C., Albaiges, J., Livingstone, D.R., 1994. 7-Ethoxyresorufin O-deethylase (EROD) activity and antioxidant enzyme activities in larvae of sardine (Sardina pilchardus) from the north coast of Spain. Mar. Pollut. Bull. 28, 299-304.

Porter, N.A., Caldwell, S.E., Mills, K.A., 1995. Mechanisms of free radical oxidation of unsaturated lipids. Lipids 30, 277-290.

Radi, A.A.R., Matkovics, B., Csengeri, I., 1987. Comparative studies of the phospholipid fatty acids and the antioxidant enzyme activities in fish with different feeding habits. Comp. Biochem. Physiol. 87B, 49-54.

Rana, S.V.S., Singh, R., 1996. Species differences in glutathione-dependent enzymes in the liver and kidney of two fresh water fishes and their implications for cadmium toxicity. Ichthyol. Res. 43, 223-229.

Roche, H., Boge, G., 1993. Effects of $\mathrm{Cu}, \mathrm{Zn}$ and $\mathrm{Cr}$ salts on antioxidant enzyme activities in vitro of red blood cells of a marine fish Dicentrarchus labrax. Toxicol. In Vitro 7, 623-629.

Rossell, J.B., 1989. Measurement of rancidity. In: Allen, J.C., Hamilton, R.J. (Eds.), Rancidity in Food. Elsevier Press, London, pp. 23-65.

Roy, W.J., Matty, A.J., Bell, J.G., 1995. Tissue vitamin E concentrations during smoltification and seawater transfer in farmed Atlantic salmon, Salmo salar L. Aquacult. Nutr. 1, 51-57.

Sakai, T., Murata, H., Endo, M., Yamauchi, K., Tabata, N., Fukudome, M., 1989. 2Thiobarbituric acid values and contents of $\alpha$-tocopherol and bile pigments in the liver and muscle of jaundiced yellowtail, Seriola aquiqueradiata. Agric. Biol. Chem. 53, 1739-1740.

Sakai, T., Murata, H., Yamauchi, K., Sekiya, T., Ukawa, M., 1992. Effects of dietary lipid peroxides contents on in vivo lipid peroxidation, $\alpha$-tocopherol contents, and superoxide dismutase and glutathione peroxidase activities in the liver of yellowtail. Nippon Suisan Gakaishi 58, 1483-1486. 
Sekiya, T., Murata, H., Sakai, T., Yamauchi, K., Yamashita, K., Ukawa, M., Kanai, M., Shimada, M. 1991. An attempt to control lipid peroxidation in the tissues of yellowtails and to enhance their biological protective ability by feeding high $\alpha$-tocopherol brown meal. Nippon Suisan Gakkaishi 57, 287-292.

Sohal, R.S., Wolfe, L.S., 1986. Lipofuscin: characteristics and significance. In: Swaab, D.F., Fliers, E., Mirmiran, M., Van Gool, W.A., Van Haaren, F. (Eds). Progress in Brain Research, Elsevier Science, Amsterdam, pp.171-183.

Sohal, R. S., Brunk, U. T., 1990. Lipofuscin as an indicator of oxidative stress and aging. In Porta, E.A. (Ed.), Lipofuscin and Ceroid Pigments. Plenum Press, New York, pp.17-30.

Stéphan, G., Guillaume, J., Lamour, F., 1995. Lipid peroxidation in turbot (Scophthalmus maximus) tissue: effect of dietary vitamin $\mathrm{E}$ and dietary $\mathrm{n}-6$ and $\mathrm{n}-3$ polyunsaturated fatty acids. Aquaculture 130, 251-268.

Tappel, A.L., 1975. Lipid peroxidation and fluorescent molecular damage to membranes. In: Trump, B.F., Arstila, A.U. (Eds.). Pathology of Cell Membranes, Vol. I. Academic Press, New York, pp. 145-173.

Tocher, D.R., Harvie, D.G., 1988. Fatty acid composition of the major phosphoglycerides from fish neural tissues; (n-3) and (n-6) polyunsaturated fatty acids in rainbow trout (Salmo gairdneri) and cod (Gadus morhua) brains and retinas. Fish Physiol. Biochem. 5, 229-239.

Yin, D., 1995. Studies on age pigments evolving into a new theory of biological aging. Gerontology 41, 159-172.

Watanabe, T., Takashima, F., Ogino, C., Hibiya, T., 1970. Effect of $\alpha$-tocopherol on carp. Nippon Suisan Gakkaishi 36, 623-630.

Zar, J.H., 1984. Biostatistical Analysis, 2nd edition. Prentice-Hall, Englewood Cliffs, NJ. 
Legends to Figures

Fig.1. Dry weight (top panel), lipid composition (middle panel) and fatty acid composition (bottom panel) of Dentex dentex eggs and unfed larvae from hatch (L0) to day 9 after hatch (L9). Results are all presented in absolute terms of $\mu \mathrm{g}$ per individual larvae and are means \pm SD $(n=3)$. TL, total lipid; PL, total polar lipid: NL, total neutral lipid; SFA, total saturated fatty acid; MUFA, total monounsaturated fatty acids; PUFA, total polyunsaturated fatty acids. Due to the large variation in individual dry weights the data were not statistically significant. The absolute data for lipid and fatty acid contents were calculated from percentage data and as such show obvious highly significant differences although levels of significance were omitted from the figures for clarity.

Fig.2. Contents of vitamin E (top panel), malondialdehyde (MDA) (middle panel) and lipidsoluble fluorescent products (LSFP) (bottom panel) of Dentex dentex eggs and unfed larvae from hatch (L0) to day 9 after hatch (L9). Results are all presented in terms of per individual larvae and are means \pm SD $(n=3)$. 350-445 $\mathrm{nm}$, characteristic of lipid complexes formed by the cross linking of the aldehyde groups of MDA with amino groups of phosphatidylserine; 400-455 nm, characteristic of lipid complexes formed by the cross linking of the aldehyde groups of MDA with amino groups of phosphatidylethanolamine. Individual data points for a given parameter with different superscript letters are significantly different $(\mathrm{P}<0.05)$.

Fig.3. Contents of antioxidant (vit E) and peroxidation products (malondialdehyde, MDA and lipid-soluble fluorescent products, LSFP) relative to the polyunsaturated fatty acid (PUFA) content of Dentex dentex eggs and unfed larvae from hatch (L0) to day 9 after hatch (L9). 
Fig.4. Activities of enzymes of the antioxidant systems in Dentex dentex eggs and unfed larvae from hatch (L0) to day 9 after hatch (L9). Catalase (top panel), Glutathione peroxidase (GPX) with hydrogen peroxide (HP) or cumene hydroperoxide $(\mathrm{CH})$ as substrates and glutathione-S-transferase (middle panel) and total superoxide dismutase (SOD) and glutathione reductase (GR) (bottom panel). Results are all presented in $\mu \mathrm{mol} / \mathrm{min} / \mathrm{mg}$ protein other than SOD which is presented as units/min/mg protein and are means \pm SD $(n=3)$. Individual data points for a given activity with different superscript letters are significantly different $(\mathrm{P}<0.05)$. For clarity in the middle panel, significance of differences are shown for only the data for total GPX $[\mathrm{GPX}(\mathrm{CH})]$ and not GPX(HP). 


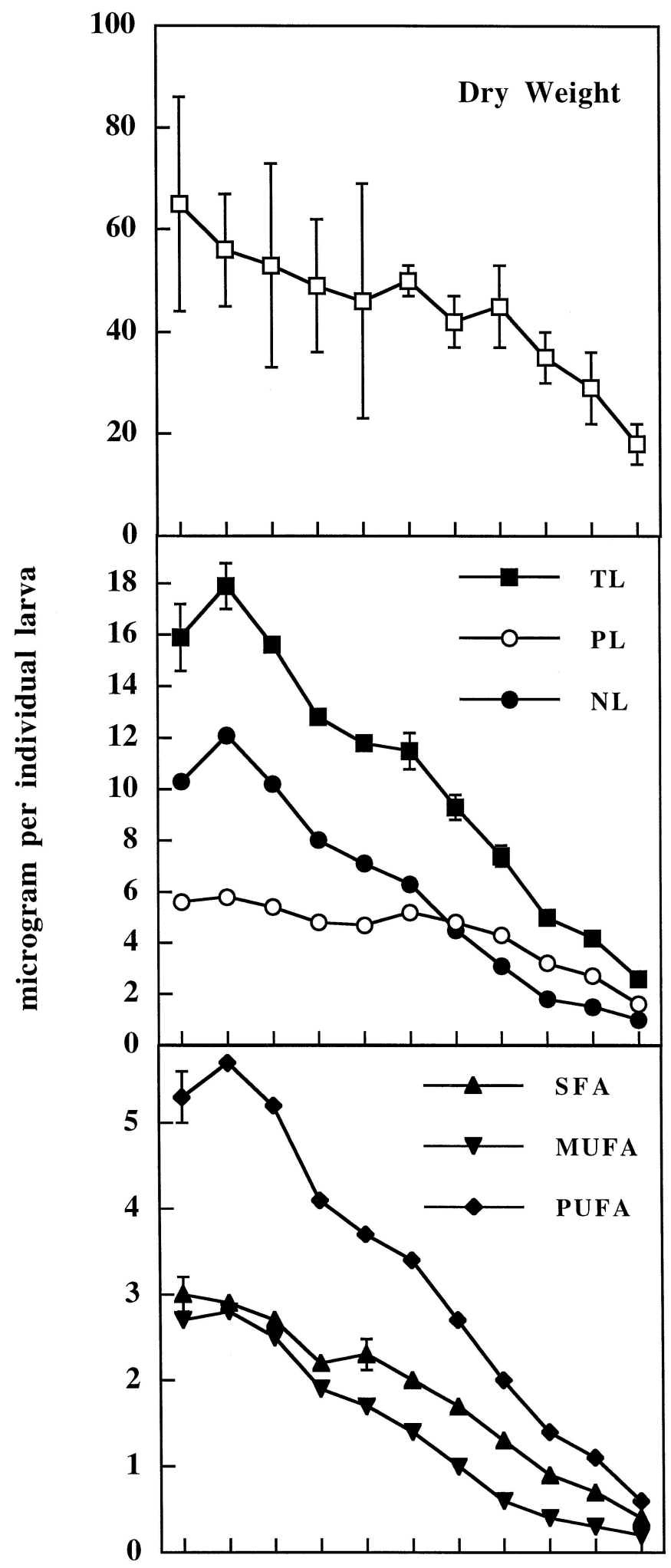

$\begin{array}{lllllllllll}\text { Egg L0 } & \text { L1 } & \text { L2 } & \text { L3 } & \text { L4 } & \text { L5 } & \text { L6 } & \text { L7 } & \text { L8 } & \text { L9 }\end{array}$

Stage/Time after hatch (days)

Page 24 


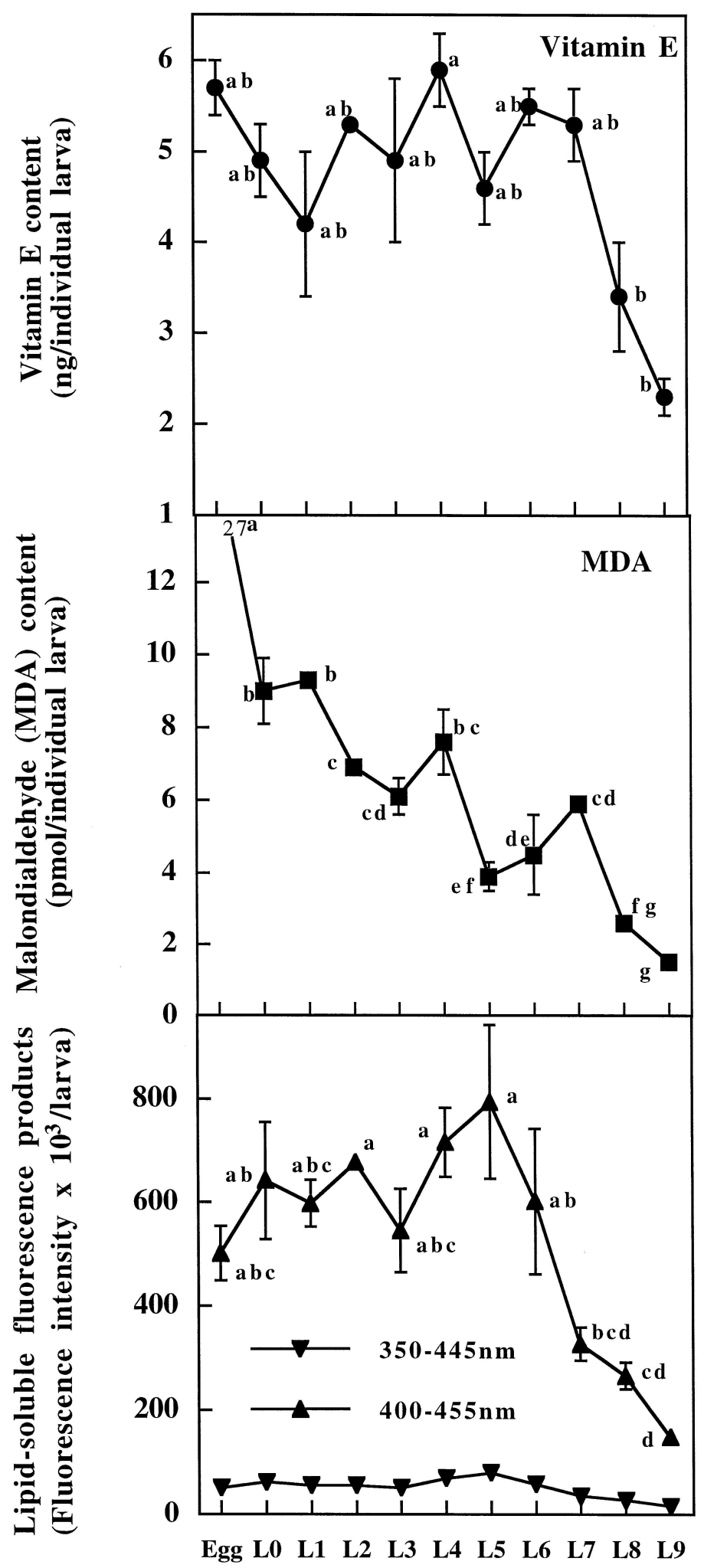

Stage/Time after hatch (days)

Page 25 


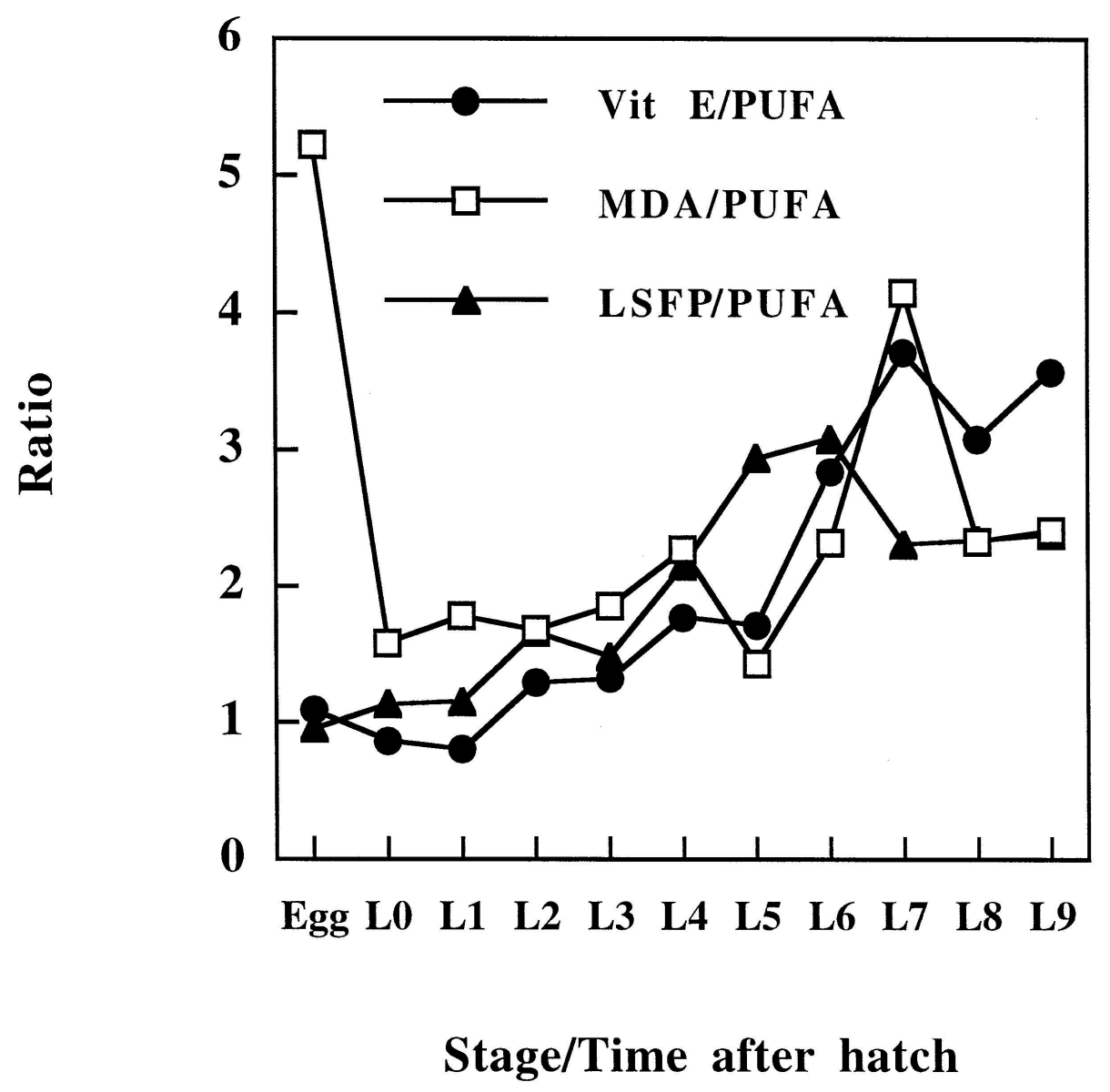

Page 26 


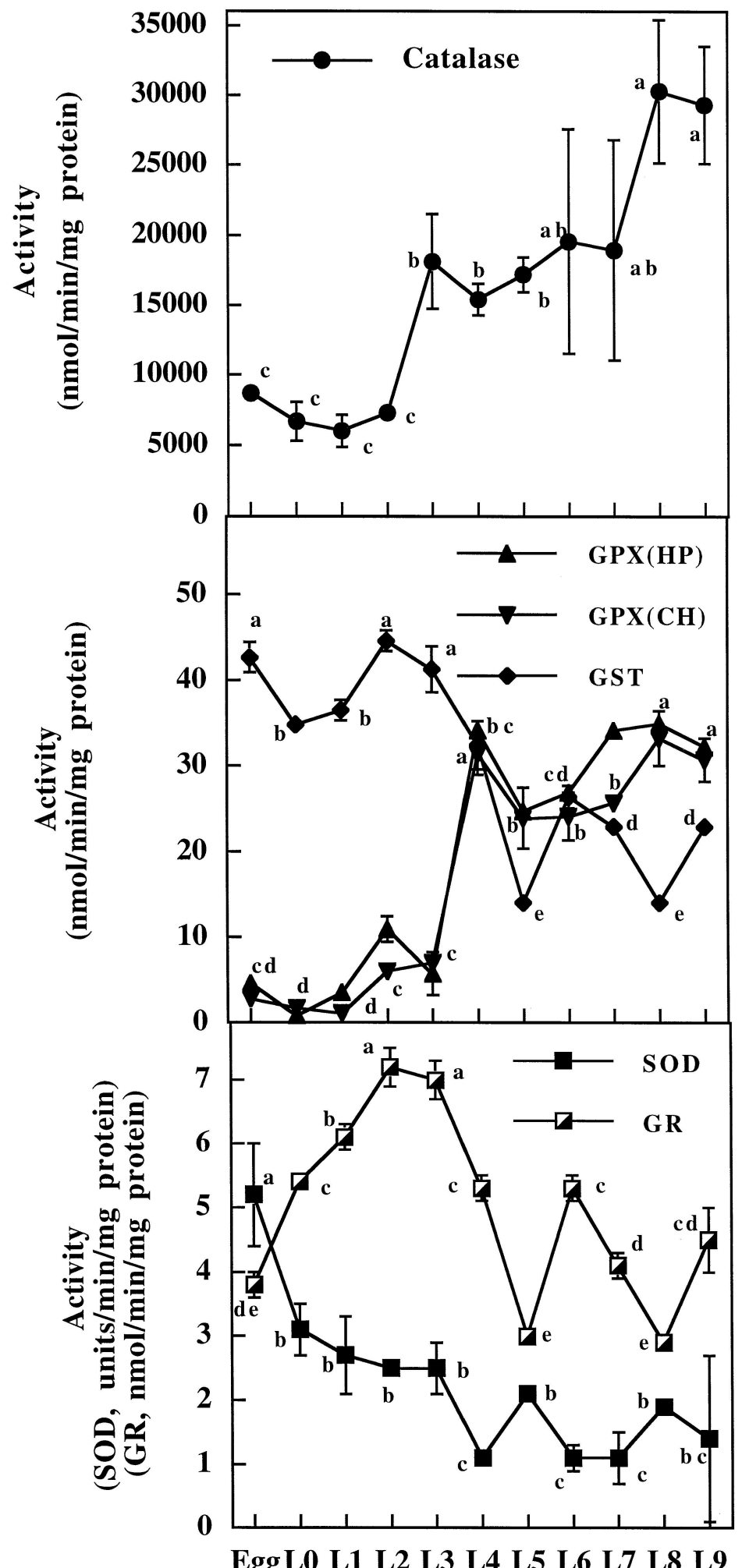

Stage

Page 27 